\title{
STUDIES ON THE INITIATION OF BLOOD COAGULATION. II. AN ANTICOAGULANT INHIBITING THE ACTIVATION OF A PLASMA THROMBOPLASTIC FACTOR ${ }^{1}$
}

\author{
By C. LOCKARD CONLEY, OSCAR D. RATNOFF, CHARLES E. ELLICOTT, AND \\ ROBERT C. HARTMANN
}

(From the Department of Medicine, The Johns Hopkins University and Hospital)

(Submitted for publication April 3, 1950; accepted, June 5, 1950)

Evidence has accumulated that the initiation of blood clotting may involve the participation of a plasma thromboplastic factor capable of inducing the conversion of prothrombin to thrombin (1-7). The activation of this factor does not appear to require the presence of blood platelets (8), although platelets seem to potentiate its action (8-10). Elucidation of the rôle of this plasma factor has largely depended upon the observation of apparent alterations in its activity in pathologic states. Thus, the coagulation defect in hemophilia seems best explained by deficient activity of a plasma thromboplastic factor (11).

In the experiments to be described, further information has been provided by the study of an anticoagulant with peculiar properties. This anticoagulant was present in the plasma of a patient with an unusual hemorrhagic disorder. The patient's plasma inhibited the coagulation of normal blood. The inhibitory substance was precipitable with a globulin fraction. It did not appear to inhibit thrombin, prothrombin, or accelerator globulin, nor did it inhibit the activity of platelets or of thromboplastin from a variety of sources. However, the anticoagulant did inhibit the clot accelerating effect of glass surfaces on normal platelet-free plasma. The mode of action of this anticoagulant can be explained best by assuming the presence in platelet-free plasma of a thromboplastic mechanism.

\section{CASE REPORT}

The patient was a 37 year old housewife whose case history was previously described by Chargaff and West (12). There was no family history of bleeding, nor did either of her two children display

1 This investigation was supported in part by a research grant from the Division of Research Grants and Fellowships of the National Institutes of Health, U. S. Public Health Service and was in part carried out under contract with the Office of Naval Research, United States Navy. hemorrhagic manifestations. The patient had three spontaneous abortions at ages 21,23 , and 30 years. and she was delivered of normal children at the ages of 23 and 32. Following the third abortion the patient bled profusely and was transfused with $500 \mathrm{cc}$. of whole blood. Since that time she had had persistent evidence of a hemorrhagic diathesis with vaginal bleeding, cutaneous ecchymoses, deforming hemarthroses, bleeding gums, and hemorrhage following tooth extractions. She had been treated elsewhere without benefit with multiple blood transfusions, antihemophilic globulin, splenic irradiation, protamine sulfate, "Rutarbin," "Koagamin," and ovarian irradiation. On physical examination the findings of note were cutaneous ecchymoses, and limitation of motion and deformity of several of the large joints attributable to old hemarthroses. The remainder of the physical examination was not remarkable. The whole blood clotting time was prolonged to between three and five hours, but the prothrombin time was normal.

\section{METHODS}

The term "plasma thromboplastic factor" is employed to designate the substance or substances in plasma which under certain conditions may initiate the conversion of prothrombin to thrombin. The substance responsible for this activity has not been isolated or identified, but is apparently related to the antihemophilic factor. In this report the term "native plasma" refers to plasma obtained without the addition of anticoagulant and freed from formed elements by centrifugation.

Essentially platelet-free plasma was obtained by methods previously described $(7,8)$. With the subject in a fasting state, blood was drawn without anticoagulant using silicone-treated equipment. The formed elements including the platelets were removed by high-speed centrifugation at low temperature. Such plasma contained less than 50 platelets per $\mathrm{cmm}$. Plasma prepared in this manner from the blood of the patient under study was incoagulable when incubated indefinitely at $37^{\circ} \mathrm{C}$. in Pyrex glass tubes. On the other hand, as previously observed (7), plasma similarly prepared from the blood of 
normal subjects clotted relatively promptly in glass tubes at $37^{\circ} \mathrm{C}$.

The buffer solution used in these experiments was composed of 7.3 grams sodium chloride, 2.76 grams barbital, and 2.06 grams sodium barbital diluted to a volume of 1 liter with distilled water. The $\mathrm{pH}$ of this isotonic solution was 7.5.

The anticoagulant activity of plasma and plasma fractions prepared from the patient's blood was assayed by determining their clot-retarding effect on normal whole blood (13).

The patient's native plasma was dialyzed in 1 inch No-jax cellophane sausage casings against barbital buffer at $2^{\circ} \mathrm{C}$. The cellophane bag was rotated continually during this procedure by an electric motor. Nine and one-half $\mathrm{ml}$. of plasma were dialyzed against $350 \mathrm{ml}$. of buffer for 24 hours, the buffer solution being completely changed five times. The patient's plasma remained fluid during and after dialysis.

Protein fractions of the patient's plasma were obtained by precipitation with ammonium sulfate. Essentially platelet-free plasma was citrated. It was then diluted with an ammonium sulfate solution which had been saturated at room temperature and neutralized to $\mathrm{pH} 7$ with concentrated ammonium hydroxide. The fraction precipitated by $25 \%$ saturation with ammonium sulfate was separated by centrifugation at room temperature. Successive fractionations of the supernatant fluid were carried out with increasing concentrations of ammonium sulfate. The precipitates obtained were redissolved in buffer and dialyzed for one hour against running tap water and then against frequent changes of buffer for 16 hours. The supernatant fluid remaining after half saturation with ammonium sulfate was also dialyzed in the same manner. When dialysis was completed, the volume of each fraction was measured.

In the original preparation, the fraction containing the most anticoagulant activity was that precipitated between $25 \%$ and $33 \%$ saturated ammonium sulfate. Therefore, this fraction was again prepared in the following manner: Native plasma was oxalated and filtered through a Seitz ST filter in order to decrease the concentration of prothrombin. The filtrate was diluted with an equal volume of water, and ammonium sulfate added to provide a final concentration of $25 \%$. The precipitate was removed by centrifugation and discarded. Ammonium sulfate was then added to the supernatant fluid to give a final concentration of $33 \%$, and the mixture allowed to stand for three hours at $4^{\circ} \mathrm{C}$. The supernate was decanted after centrifugation and the precipitate redissolved in barbital buffer. This solution was dialyzed for four hours against running tap water and then for 16 hours against frequent changes of barbital buffer.

The effect of protamine sulfate on the anticoagulant activity of the patient's plasma was tested. A solution of protamine sulfate ${ }^{2}$ was serially diluted with buffer. One-tenth $\mathrm{ml}$. of the protamine solution was mixed with

2 Protamine was obtained through the courtesy of Eli Lilly and Company, Indianapolis.
$0.1 \mathrm{ml}$. of the patient's native plasma in glass tubes. One ml. portions of fresh normal blood were added and the clotting times determined in duplicate at $37^{\circ} \mathrm{C}$. Final concentrations of protamine tested were $80,16,8,0.8$, and 0.4 micrograms per $\mathrm{ml}$.

Precipitin tests were performed in capillary tubes. The patient's oxalated native plasma was serially diluted with buffer and tested with normal oxalated plasma and with normal serum. The plasmas were oxalated by the addition of one part of $0.1 \mathrm{M}$ sodium oxalate to nine parts of plasma. The capillary tubes were allowed to stand at room temperature for 24 hours and were observed for the presence of precipitate at frequent intervals during that time.

Thromboplastin was prepared from rabbit brain and from human brain by techniques previously described (14).

A suspension of macerated platelets was prepared from hemophilic blood in the following manner. Blood was obtained without anticoagulant from a fasting hemophiliac and centrifuged at low speed for five minutes in siliconetreated test tubes. The supernatant plasma was removed and found to contain 428,000 platelets per cmm. Eighteen $\mathrm{ml}$. of this plasma were then recentrifuged at 10,500 RPM in a Servall Superspeed angle centrifuge for 10 minutes. The sediment, which consisted of platelets, was washed with buffer and recentrifuged. It was then macerated with a glass mortar and pestle and resuspended in $3.5 \mathrm{ml}$. of buffer.

The crushed glass used in these experiments was prepared from Pyrex test tubes of the same lot used for the determination of clotting times. Particles which passed through a 50 mesh screen but which were retained by a 100 mesh screen were employed.

The clotting time of recalcified oxalated plasma was determined in glass tubes at $37^{\circ} \mathrm{C}$. Blood was oxalated by the addition of one part of $0.1 \mathrm{M}$ sodium oxalate to nine parts of whole blood and the plasma separated by centrifugation. One-half $\mathrm{ml}$. of this plasma was recalcified with $0.1 \mathrm{ml}$. of $0.1 \mathrm{M}$ calcium chloride in the presence of $0.1 \mathrm{ml}$. of the solution being tested.

\section{RESULTS}

\section{Inhibition of coagulation of normal blood by the patient's plasma}

The presence of anticoagulant activity in the patient's plasma was demonstrated by its inhibitory effect on the clotting of normal blood, as shown in Table I. As little as one part of the patient's plasma in 200 parts of normal blood prolonged significantly the clotting time of the latter.

\section{Anticoagulant activity of plasma protein frac- tions}

There was no appreciable loss of clot inhibitory activity when the patient's plasma was dialyzed at low temperature for 24 hours against frequent 
TABLE I

Anticoagulant effect of the patient's plasma on normal blood Clotting time (minutes) in glass tubes at $37^{\circ} \mathrm{C}$ of $1 \mathrm{ml}$. portions of normal blood to which was added the patient's native plasma in the amounts indicated

\begin{tabular}{c|c|c|c|c|c}
\hline Buffer & \multicolumn{5}{|c}{ Patient's plasma } \\
\hline $0.2 \mathrm{ml}$. & $0.001 \mathrm{ml}$. & $0.005 \mathrm{ml}$. & $0.01 \mathrm{ml}$. & $0.1 \mathrm{ml}$. & $0.2 \mathrm{ml}$. \\
\hline 18 & 17 & 30 & 48 & 60 & $>180$ \\
19 & 19 & 31 & 46 & 78 & $>180$ \\
21 & 20 & 33 & 42 & 80 & $>180$ \\
\hline
\end{tabular}

* Determinations in triplicate.

changes of barbital buffer. A crude fractionation of the plasma was performed by precipitating its protein components with various concentrations of ammonium sulfate. With this technique it was observed that anticoagulant activity was present to the greatest degree in the fraction precipitated between $25 \%$ and $33 \%$ saturated ammonium sulfate (Table II). Some clot inhibitory activity was also present in the fraction precipitated between $33 \%$ and $50 \%$ ammonium sulfate. The active principle could not be reprecipitated with the euglobulins by diluting the fraction with 19 volumes of water and acidifying to $\mathrm{pH} 5.2$ with acetic acid. Although the anticoagulant property of the patient's plasma was associated with the globulin fraction, the serum globulin as measured by the Howe technique (15) was not appreciably increased. By this method the albumin concentration was 4.6 grams and the globulin 3.1 grams per $100 \mathrm{ml}$. of serum. Furthermore, electrophoretic analysis of the patient's plasma did not reveal any abnormality. ${ }^{3}$

${ }^{8}$ Electrophoretic analysis was performed through the courtesy of Dr. Bacon Chow.

TABLE II

Anticoagulant effect of crude fractions of the patient's plasma Clotting time (minutes) in glass tubes at $37^{\circ} \mathrm{C}$ of $1 \mathrm{ml}$. portions of Clotting time (minutes) in glass tubes at $37^{\circ} \mathrm{C}$ of $1 \mathrm{ml}$. portions of
normal blood to which were added $0.1 \mathrm{ml}$. portions of the fraction indicated.*

\begin{tabular}{c|c|c|c|c}
\hline \multirow{3}{*}{ Buffer } & \multicolumn{4}{|c}{ Ammonium sulfate fraction } \\
\cline { 2 - 5 } & $0-25 \%$ & $25-33 \%$ & $33-50 \%$ & $>50 \%$ \\
\hline 10 & 14 & 60 & 21 & 15 \\
10 & 14 & 45 & 14 & 16 \\
\hline
\end{tabular}

* Final concentration of the fraction was approximately $1 / 100$ original plasma concentration.

\section{Properties of the anticoagulant}

The anticoagulant activity present in the patient's plasma persisted after the plasma was heated at $56^{\circ} \mathrm{C}$. for 30 minutes. Heating the globulin fraction with the greatest anticoagulant activity to $56^{\circ} \mathrm{C}$. for 30 minutes did not alter its activity, but there was some loss at $65^{\circ} \mathrm{C}$. for 30 minutes. After heating at $80^{\circ} \mathrm{C}$. for 10 minutes, the globulin fraction was inert in all concentrations tested. The patient's native platelet-deficient plasma was stored at about $5^{\circ} \mathrm{C}$. for three months in silicone-treated test tubes without the addition of chemical anticoagulant. At the end of that time this plasma was still fluid. The stored plasma retained its anticoagulant activity, one part of plasma significantly prolonging the clotting time of 100 parts of fresh normal blood. Plasma similarly stored at $37^{\circ} \mathrm{C}$. for 24 hours showed no loss of anticoagulant activity. However, when the patient's plasma was oxalated prior to storage at $5^{\circ} \mathrm{C}$., there was a marked loss of anticoagulant activity after three months.

The effect of protamine sulfate on the anticoagulant activity of the patient's plasma was tested. The preparation of protamine employed had been demonstrated to overcome the clot-retarding action of heparin. However, in concentrations ranging from 0.4 to 80 micrograms per ml., it was ineffective in altering significantly the anticoagulant property of the patient's plasma. This observation indicates that the anticoagulant present in the patient's plasma did not resemble heparin.

The circulating anticoagulant occasionally encountered in hemophilic patients has been said to be an antibody (16). The anticoagulant in the blood of the patient under study resembled that found in these hemophiliacs. For this reason studies were performed to determine whether the patient's plasma contained antibodies against a component of normal plasma or serum. No precipitins could be demonstrated when the patient's plasma was tested with normal oxalated plasma from one subject, normal pooled plasma and with antihemophilic globulin. A precipitate was formed when the patient's plasma was set up with normal serum. It seemed likely that this precipitate was fibrin. For this reason the patient's plasma was clotted with thrombin and the serum then tested with normal serum. Under these conditions no precipitins could be demonstrated in any dilution. 


\section{Mode of action of the anticoagulant}

The mode of action of the circulating anticoagulant was tested by noting its effect on various known clotting factors. When thrombin ${ }^{4}$ of bovine origin was added to the patient's oxalated plasma, clotting occurred as promptly as in normal plasma under the same conditions (Table III).

TABLE III

Rate of clotting of the patient's oxalated plasma by thrombin

Clotting time (seconds) of $0.2 \mathrm{ml}$. oxalated plasma on adding $0.2 \mathrm{ml}$ thrombin solution

\begin{tabular}{l|c|c|c|c}
\hline \multirow{2}{*}{$\begin{array}{c}\text { Source of } \\
\text { plasma }\end{array}$} & \multicolumn{3}{|c}{ Thrombin concentration (units/ml.) } \\
\cline { 2 - 4 } & 10 & 5 & 2.5 & 1.25 \\
\hline Patient & 15 & 26 & 50 & 110 \\
& 16 & 25 & 60 & 110 \\
\hline $\begin{array}{c}\text { Normal } \\
\text { control }\end{array}$ & 12 & 28 & 45 & 120 \\
& 14 & 32 & 50 & 100 \\
\hline
\end{tabular}

Therefore, it appeared that the anticoagulant did not inhibit the activity of thrombin.

The clot accelerating effect of thromboplastin derived from rabbit brain was tested. This thromboplastin shortened the clotting time of recalcified oxalated plasma to the same degree in this patient

TABLE IV

Rate of clotting of the patient's native plasma by human brain thromboplastin

\begin{tabular}{|c|c|c|c|c|c|}
\hline \multicolumn{6}{|c|}{$\begin{array}{l}\text { Clotting time (seconds) at } 37^{\circ} \mathrm{C} \text {. of } 0.1 \mathrm{ml} \text {. plasma on adding } 0.1 \mathrm{ml} \\
\text { human brain thromboplastin }\end{array}$} \\
\hline \multirow{2}{*}{$\begin{array}{l}\text { Source of } \\
\text { plasma }\end{array}$} & \multicolumn{5}{|c|}{ Thromboplastin concentration } \\
\hline & Undiluted & $1: 200$ & $1: 800$ & $1: 3200$ & $1: 6400$ \\
\hline Patient & $\begin{array}{l}14 \\
16\end{array}$ & $\begin{array}{l}34 \\
32\end{array}$ & $\begin{array}{l}55 \\
57\end{array}$ & $\begin{array}{l}110 \\
130\end{array}$ & $\begin{array}{l}180 \\
180\end{array}$ \\
\hline $\begin{array}{l}\text { Normal } \\
\text { control }\end{array}$ & $\begin{array}{l}12 \\
13\end{array}$ & $\begin{array}{l}34 \\
34\end{array}$ & $\begin{array}{l}57 \\
61\end{array}$ & $\begin{array}{l}111 \\
130\end{array}$ & $\begin{array}{l}160 \\
200\end{array}$ \\
\hline
\end{tabular}

and in normal controls. Moreover, addition of the same thromboplastin in a wide range of concentrations clotted the patient's native platelet-deficient plasma as promptly as normal plasma. In other experiments thromboplastin derived from human brain gave the same results (Table IV). Russell

4 Thrombin was obtained through the courtesy of Upjohn Company, Kalamazoo, Michigan.
TABLE V

Clot promoting effect of Russell viper venom and of crystalline trypsin on the patient's native plasma

Clotting time (seconds) at $37^{\circ} \mathrm{C}$. of $0.5 \mathrm{ml}$. portions of native plasma on adding $0.05 \mathrm{ml}$. of the test substance.

\begin{tabular}{l|c|c}
\hline \multicolumn{1}{c|}{ Source of plasma } & Stypven (1:5) & Trypsin (20 mgm/cc.) \\
\hline Patient & 140 & 28 \\
& 150 & 26 \\
\hline Normal & 154 & 35 \\
control & 140 & 30 \\
\hline
\end{tabular}

viper venom ${ }^{5}$ and crystalline trypsin ${ }^{6}$ also clotted the patient's native platelet-deficient plasma as readily as normal plasma (Table V). These experiments indicate that the anticoagulant does not inhibit the conversion of prothrombin to thrombin, nor does it interfere with the activity of accelerator globulin or of thromboplastin.

Further studies were carried out to determine whether the anticoagulant was capable of inhibiting the thromboplastin derived from platelets. In these experiments suspensions of macerated platelets from hemophilic blood were employed. Hemophilic plasma is presumably deficient in plasma thromboplastic factor, so that hemophilic platelets can be assumed to be virtually free of this plasma component. The addition of a suspension of washed and macerated hemophilic platelets to normal platelet-deficient plasma caused prompt clotting. The presence of the patient's plasma did not

5 Stypven, Wellcome Physiological Research Laboratories, Beckenham, England.

- Crystalline trypsin: Armour Laboratories, Chicago, Illinois.

TABLE VI

Effect of the patient's plasma on the coagulant action of a suspension of macerated platelets

Clotting time (seconds) at $37^{\circ} \mathrm{C}$. of $0.8 \mathrm{ml}$. portions of normal plateletdeficient plasma to which were added the patient's plasma and the platelet suspension in the amounts indicated

\begin{tabular}{c|c|c}
\hline \multirow{2}{*}{ Platelet suspension* } & \multicolumn{2}{|c}{ Patient's plasma } \\
\cline { 2 - 3 } & 0 & $0.1 \mathrm{ml}$. \\
\hline 0 & 1080 & $\infty$ \\
& 1260 & $\infty$ \\
\hline $0.1 \mathrm{ml}$. & 120 & 120 \\
& 130 & 100
\end{tabular}

* The platelet suspension was prepared from hemophilic blood. Final concentration of macerated platelets approximately 200,000 per $\mathrm{cmm}$. 
TABLE VII

Anticoagulant effect of the patient's plasma on normal platelet-deficient plasma

Clotting time (minutes) at $37^{\circ} \mathrm{C}$. of $0.8 \mathrm{ml}$. portions of normal plateletdeficient plasma* in glass tubes. The patient's plasma and crushed glass were present in the amounts indicated.

\begin{tabular}{c|c|c}
\hline \multirow{2}{*}{ Crushed glass } & \multicolumn{2}{|c}{ Patient's plasma } \\
\cline { 2 - 3 } & 0 & $0.1 \mathrm{ml}$ \\
\hline 0 & 12 & $\infty$ \\
$500 \mathrm{mgm}$. & 5 & 45 \\
\hline
\end{tabular}

* Platelet count of this native plasma was less than 100 per cmm.

inhibit the clot accelerating effect of the platelet suspension (Table VI).

Finally, experiments were performed to determine whether a plasma thromboplastic factor was inhibited by the anticoagulant. Previous studies have shown that normal plasma clots on contact with glass surfaces in the virtual absence of platelets (7). The rate of clotting of such plasma was found to be related to the surface area of the glass in contact with the plasma (8). However, platelet-deficient plasma from the patient under study failed to clot in glass tubes even when crushed glass was added. Furthermore, the addition of small amounts of the patient's plasma to normal platelet-deficient plasma retarded the clotting of the latter (Table VII).

When the patient's plasma was diluted with buffer in glass tubes, coagulation did not occur in any dilution tested. The addition of crushed glass to the undiluted plasma likewise failed to induce coagulation. However, when crushed glass was added to appropriately diluted plasma, coagulation did occur (Table VIII). This observation suggests that the patient's plasma contained po-

TABLE VIII

Clot promoting effect of glass on the patient's diluted plasma

Clotting time (minutes) at $37^{\circ} \mathrm{C}$. of $1 \mathrm{ml}$. portions of dilutions of the Clotting time (minutes) at $37^{\circ} \mathrm{C}$. of $1 \mathrm{ml}$. portions of dilutions of the
patient's plasma. The clotting times were determined in glass tubes, patient's plasma. The clotting times wer.

\begin{tabular}{c|c|c|c|c}
\hline \multicolumn{5}{|c}{ Plasma concentration* } \\
\hline $100 \%$ & $50 \%$ & $30 \%$ & $20 \%$ & $10 \%$ \\
\hline$\infty$ & 60 & 60 & 360 & $\infty$ \\
$\infty$ & 70 & 60 & 360 & $\infty$ \\
\hline
\end{tabular}

* Patient's native plasma was diluted with buffer to the concentration indicated. tential thromboplastic activity. In undiluted plasma the circulating anticoagulant apparently inhibited the appearance of effective thromboplastic activity even upon the addition of crushed glass. However, when the plasma was diluted so that the concentration of anticoagulant was diminished, thromboplastic activity did appear when crushed glass was added.

It is an old observation that recalcified oxalated plasma clots more rapidly than unoxalated blood. The mechanism of this acceleration is not known. The effect of the patient's circulating anticoagulant on the recalcified plasma clotting time was tested (Table IX). The coagulation of recalcified oxalated normal plasma was inhibited by small amounts of the patient's plasma. When crushed glass was added, this effect largely disappeared.

TABLE IX

Anticoagulant effect of the patient's plasma on recalcified oxalated normal plasma

Clotting time (seconds) at $37^{\circ} \mathrm{C}$. of $0.5 \mathrm{ml}$. portions of oxalated normal plasma on recalcification with $0.1 \mathrm{ml}$. M/10 calcium chloride. The patient's plasma and crushed glass were present in the amounts indicated.

\begin{tabular}{c|c|c}
\hline \multirow{2}{*}{ Crushed glass } & \multicolumn{2}{|c}{ Patient's plasma } \\
\cline { 2 - 3 } & 0 & $0.1 \mathrm{ml}$. \\
\hline 0 & 480 & $\infty$ \\
& 480 & $\infty$ \\
\hline 400 mgm. & 80 & 150 \\
& 90 & 180 \\
\hline
\end{tabular}

Thus, in oxalated plasma as in native plasma the addition of crushed glass overcame the inhibitory effect of the diluted anticoagulant.

\section{DISCUSSION}

Previous studies have suggested the presence in plasma of a soluble factor necessary for the appearance of normal thromboplastic activity. The impaired coagulation in hemophilia is apparently related to deficient activity of such a factor. In hemophilia, the blood is known to contain normal amounts of prothrombin, accelerator globulin, fibrinogen, and platelets. The coagulation defect in this disease can be overcome by a substance present in normal plasma (11). Hemophilic blood is known to clot normally in the presence of various thromboplastic agents. Therefore, it 
appears likely that the defective coagulation in hemophilia is attributable to deficient thromboplastic activity.

The mode of action of the plasma factor deficient in hemophilia is not yet clearly defined. The data from recent experimental studies provide convincing evidence that for normal clotting both a plasma factor and platelets are necessary $(7,17,18)$. Brinkhous (18) has suggested that the plasma factor serves to lyse platelets, which in turn release thromboplastin. Quick (17), on the other hand, is of the opinion that the plasma factor is a "thromboplastinogen" which is converted to active thromboplastin by an enzyme released from disintegrating platelets.

The respective rôles of the platelets and of the plasma factor have been evaluated by studies of normal plasma from which the platelets have been removed (8). These experiments indicated that essentially platelet-free plasma regularly clotted when in contact with glass surfaces, although it was often incoagulable when kept in siliconetreated vessels. The rate of clotting of such platelet-deficient plasma was a function of the surface area of the glass to which it was exposed. These studies have been interpreted to suggest that the plasma factor was present in circulating blood in an inactive state, and could be activated in some unknown manner upon contact with glass surfaces. The presence of platelets was not necessary for this activation, although the addition of platelets tremendously accelerated the formation of thrombin.

Further evidence in support of the existence of a potentially thromboplastic plasma factor has been provided by the study of certain patients whose plasma contained a circulating anticoagulant (12, 16, 19-26). Such an anticoagulant, present in the plasma of the patient described in this report, did not inhibit the action of thrombin, prothrombin, accelerator globulin, or a variety of thromboplastic substances including human and rabbit brain, platelet suspensions and Russell viper venom. Nevertheless, this anticoagulant was effective in retarding the coagulation of normal blood. The action of the anticoagulant, then, must have been exerted at an early stage of the clotting process. The data suggest that the anticoagulant prevented the appearance of thromboplastic activity in shed blood.
In previous studies it has been shown that essentially platelet-free human plasma clots when placed in glass tubes $(7,8)$. Platelets thus appear not to be necessary for the initiation of clotting. The present study provides further support of this belief. The anticoagulant under study inhibited the coagulation of normal platelet-deficient plasma, although it had no demonstrable inhibitory effect against thromboplastin derived from platelets.

The anticoagulant described was precipitated with a globulin fraction of plasma. It was nondialyzable, and was destroyed by heating at $80^{\circ} \mathrm{C}$. for 10 minutes. These properties suggest that the anticoagulant activity was associated with a protein. Precipitin studies did not provide any evidence that the clotting inhibitor was an antibody against a component of normal plasma.

\section{SUM MARY}

Evidence is presented which substantiates the view that platelet-free plasma contains a factor which is potentially thromboplastic. An anticoagulant is described which was present in the plasma of a patient with an atypical hemorrhagic diathesis. This anticoagulant retarded the clotting of normal blood. It did not inhibit the action of thrombin, prothrombin, accelerator globulin, platelets, or thromboplastin derived from various sources. The clot-inhibiting effect seems best explained by assuming that the anticoagulant inhibits the action of the plasma thromboplastic factor.

\section{BIBLIOGRAPHY}

1. Bordet, J., and Gengou, O., Recherches sur la coagulation du sang et les sérums anticoagulants. Ann. Inst. Pasteur, 1901, 15, 129.

2. Gratia, A., L'action du contact sur la coagulation du sang. J. de physiol. et de path. gén., 1918, 17, 772.

3. Nolf, P., The coagulation of the blood. Medicine, 1938, 17, 381.

4. Lenggenhager, K., Irrwege der Blutgerinnungsforschung. Klin. Wchnschr., 1936, 15, 1835.

5. Feissly, R., Recherches sur la nature et l'origine de la thrombokinase plasmatique. Helvet. med. acta, 1945, 12, 215.

6. Lozner, E. L., and Taylor, F. H. L., The effect of foreign surfaces on blood coagulation. J. Clin. Invest., 1942, 21, 241.

7. Conley, C. L., Hartmann, R. C., and Morse, W. I., II, The clotting behavior of human "platelet-free" 
plasma : evidence for the existence of a "plasma thromboplastin." J. Clin. Invest., 1949, 28, 340.

8. Hartmann, R. C., Conley, C. L., and Lalley, J. S., Studies on the initiation of blood coagulation. I. The relationship of platelets to the clot-promoting effect of glass surfaces. Bull. Johns Hopkins Hosp., 1949, 85, 231.

9. Quick, A. J., Shanberge, J. N., and Stefanini, M., The role of platelets in the coagulation of the blood. Am. J. M. Sc., 1949, 217, 198.

10. Buckwalter, J. A., Blythe, W. B., and Brinkhous, K. M., Effect of blood platelets on prothrombin utilization of $\operatorname{dog}$ and human plasmas. Am. J. Physiol., 1949, 159, 316.

11. Patek, A. J., Jr., and Stetson, R. P., Hemophilia. I. The abnormal coagulation of the blood, and its relation to blood platelets. J. Clin. Invest., 1936, 15, 531.

12. Chargaff, E., and West, R., The biological significance of the thromboplastic protein of blood. J. Biol. Chem., 1946, 166, 189.

13. Conley, C. L., Hartmann, R. C., and Morse, W. I., II, Circulating anticoagulants: a technique for their detection and clinical studies. Bull. Johns Hopkins Hosp., 1949, 84, 255.

14. Brambel, C. E., Thromboplastic reagent; development of more suitable preparation for measuring accelerated clotting tendency and for use following administration of dicoumarin (3,3'-methylene-bis[4-hydroxycoumarin]). Arch. Surg., 1945, 50, 137.

15. Howe, P. E., The determination of proteins in blood -a micro method. J. Biol. Chem., 1921, 49, 109.

16. Craddock, C. G., Jr., and Lawrence, J. S., Hemophilia. A report of the mechanism of the development and action of an anticoagulant in two cases. Blood, 1947, 2, 505.

17. Quick, A. J., Studies on the enigma of the hemostatic dysfunction of hemophilia. Am. J. M. Sc., 1947, 214, 272.

18. Brinkhous, K. M., Clotting defect in hemophilia : deficiency in a plasma factor required for platelet utilization. Proc. Soc. Exper. Biol. \& Med., 1947, 66, 117.

19. Lozner, E. L., Jolliffe, L. S., and Taylor, F. H. L., Hemorrhagic diathesis with prolonged coagulation time associated with a circulating anticoagulant. Am. J. M. Sc., 1940, 199, 318.

20. Munro, F. L., and Jones, H. W., The detrimental effect of frequent transfusions in the treatment of a patient with hemophilia. Am. J. M. Sc., 1943, 206, 710.

21. Fantl, P., and Nance, M. H., An acquired haemorrhagic disease in a female due to an inhibitor of blood coagulation. M. J. Australia, 1946, 2, 125.

22. Conley, C. L., Rathbun, H. K., Morse, W. I., II, and Robinson, J. E., Jr., Circulating anticoagulant as a cause of hemorrhagic diathesis in man. Bull. Johns Hopkins Hosp., 1948, 83, 288.

23. Dieter, D. G., Spooner, M., and Pohle, F. J., Studies on an undetermined circulating anticoagulant. Case report and laboratory findings. Blood, 1949, 4, 120.

24. Soulier, J. P., and Burstein, M., Hemorrhagic diathesis associated with the presence of an anticoagulant in circulating blood. Case report and laboratory studies. Blood, 1948, 3, 1188.

25. Tzanck, A., Soulier, J. P., and Blatrix, C., Deux nouvelles observations de syndromes hémorrhagiques avec presence d'un anticoagulant circulant. Rev. d' Hématol., 1949, 4, 502.

26. Dreskin, O. H., and Rosenthal, N., A hemophilia-like disease with prolonged coagulation time and a circulating anticoagulant. Report of a case in a female. Blood, 1950, 5, 46. 